\title{
High-flow nasal oxygen therapy in adults with hypoxemia
}

\author{
Michael C. Sklar MD, Laveena Munshi MD MSc
}

Cite as: CMAJ 2019 November 11;191:E1250. doi: 10.1503/cmaj.191021

CMAJ Podcasts: author interview at https://soundcloud.com/cmajpodcasts/191021-five

\section{High-flow nasal oxygen therapy allows delivery of heated, 1 humidified oxygen at flow rates of up to $60 \mathrm{~L} / \mathrm{min}$}

In the setting of acute respiratory failure, patients may generate inspiratory flow rates greater than the flow capacity of conventional oxygen devices. Entrainment of room air may occur, diluting the intended concentration of oxygen. ${ }^{1}$ Oxygen delivery at higher flows, through high-flow nasal oxygen, can better match inspiratory flows generated, thus enabling more precise delivery of intended oxygen concentrations. ${ }^{2}$

2 High-flow nasal oxygen has unique physiologic properties

The mechanisms of benefit are multifactorial and include higher flow rates of oxygen delivery, carbon dioxide washout of nasopharyngeal dead space, humidification allowing for improved secretion clearance and decreased bronchoconstriction, and generation of positive end-expiratory pressure (Appendix 1, available at www.cmaj.ca/lookup/suppl/doi:10.1503/cmaj.191021/-/DC1). ${ }^{2}$

\section{3}

High-flow nasal oxygen can be used in a variety of clinical situations

Several studies have shown consistent reduction in work of breathing and respiratory rate in the setting of respiratory distress. ${ }^{3}$ Evidence suggests possible benefit by improving oxygenation in acute hypoxemic respiratory failure, reducing the need for intubation and 90-day mortality. ${ }^{1,4}$ High-flow nasal oxygen therapy has also been found to reduce hypoxemia during intubation and after extubation. ${ }^{1}$

High-flow nasal oxygen should be used only in highly monitored settings

High-flow nasal oxygen should be restricted to settings with high-acuity monitoring, such as emergency departments, operating rooms and intensive care units. Clinical deterioration of a patient receiving high-flow nasal oxygen (or inadvertent oxygen disconnection) is a medical emergency given the acuity of such a patient with potentially minimal respiratory reserve. ${ }^{1}$

\section{Potential uses of high-flow nasal oxygen are still expanding}

A randomized controlled trial showed survival benefit in acute respiratory failure when high-flow nasal oxygen was compared with face-mask or noninvasive ventilation. ${ }^{4}$ There is evolving evidence for its use in the extubation management of patients at high risk of extubation failure., ${ }^{1,5}$ Other potential roles exist, including during procedural sedation, and for preoxygenation and apneic oxygenation for intubation optimization. ${ }^{3}$ The utility of high-flow nasal oxygen for hypercapnic respiratory failure, such as in chronic obstructive pulmonary disease, remains unclear but is under evaluation (ClinicalTrials.gov no. NCT03033251).

\section{References}

1. Rochwerg B, Granton D, Wang DX, et al. High flow nasa cannula compared with conventional oxygen therapy for acute hypoxemic respiratory failure: a systematic review and meta-analysis. Intensive Care Med 2019; 45:563-72.

2. Goligher EC, Slutsky AS. Not just oxygen? Mechanisms of benefit from high-flow nasal cannula in hypoxemic respiratory failure. Am J Respir Crit Care Med 2017;195: 1128-31.

3. Papazian L, Corley A, Hess D, et al. Use of high-flow nasal cannula oxygenation in ICU adults: a narrative review. Intensive Care Med 2016;42:1336-49.

4. Frat J-P, Thille AW, Mercat A, et al. High-flow oxygen through nasal cannula in acute hypoxemic respiratory failure. N Engl J Med 2015;372:2185-96.

5. Stéphan F, Barrucand B, Petit P, et al. High-flow nasal oxygen vs noninvasive positive airway pressure in hypoxemic patients after cardiothoracic surgery: a randomized clinical trial. JAMA 2015;313:2331-9.

\section{Competing interests: None declared.}

This article has been peer reviewed.

Affiliation: Interdepartmental Division of Critical Care Medicine, University of Toronto, Toronto, Ont.

Correspondence to: Laveena Munshi, Laveena.Munshi@sinaihealthsystem.ca

CMAJ invites submissions to "Five things to know about ..." Submit manuscripts online at http://mc.manuscriptcentral.com/cmaj 